\title{
The Smart Technology Application Study of the Leisure Agriculture Parks
}

\author{
LifangQiao, Lili Song and Xinzheng Li ${ }^{*}$ \\ School of Horticulture and Landscape Architecture, Henan Institute of Science \\ and Technology, Xinxiang 453003, China \\ qiaolifang2002@163.com,252736256@qq.com, lixinzheng@hist.edu.cn \\ *Corresponding Author
}

\begin{abstract}
The leisure agriculture parks in China develop rapidly. The object in this paper is a leisure agriculture park in Qinyang City, Henan Province. The paper studied the framework and approach of integrating smart technology into the planning of leisure Agriculture Park. The application of smart technology centers on integrated platform, and is divided into smart breeding, smart planting, smart sunlight greenhouse, virtual park, visualization, smart logistics, smart sale modes and so on, and it forms a hierarchical structure consisting of perception layer, network layer, application layer, platform layer and service layer. Integrating smart technology into leisure Agriculture Park's planning can improve product quality, increase production management efficiency in the park, and facilitate the sustainable development of the park.
\end{abstract}

Keywords: Smart technology, Leisure Agriculture Park, Planning

\section{Introduction}

China is a large country with huge population, and the agricultural production is crucial to the national security. With the development of science and technology, China's agriculture industrial structure is continuously adjusted and improved. Agriculture does not only have food security function, but also have functions of raw material supply, employment and income growth, ecological protection, sightseeing tours and cultural inheritance [1]. The improvement of citizens' life standards and the increasing demands for agricultural recreation promote rapid development of leisure agriculture parks [2]. Many kinds of leisure agriculture parks have been established around big cities in China, such as Shanghai, Beijing, Guangzhou and Hangzhou [3]. Those parks rely on agricultural production, take leisure tourism as the main operation model, and provide distinctive leisure places for citizens. Comparatively mature large-scale parks usually possess the following functions: providing healthy and safe farm products for the public through planting fruit trees, vegetables, flowers and cultivation of poultry, livestock and fishery, providing agricultural theme activities featuring strong participation for tourists, providing food and beverage and accommodation facilities to meet the needs of tourists, molding the agricultural landscape and forming the rural landscape characteristics. How to further expand the service function of leisure agriculture parks to increase the operating efficiency and economic benefits of the park is a topic deserving research.

Since IBM first put forward the concept of "Smart City" in 2008, the application of smart technology is becoming increasingly popular [4]. Smart technology plays an important role in areas such as smart city, smart community, smart transportation [5], etc. Smart technology realizes comprehensive perception, and is widely used in Internet, generally suitable for computing and fusion application through the application of information technologies such as the Internet of Things and cloud computing represented by mobile technology. At present, smart technology has been applied in greenhouse 
construction, product traceability and precision agriculture, and so forth in agricultural production [6]. The full integration of smart technology and leisure agriculture parks can promote the sustainable development of the agricultural parks. Smart technology is widely used in agriculture industrial parks in U.S., Israel, the Netherlands and other developed countries. Since China's agriculture has a big difference compared with that of the developed countries, it is of practical significance to study smart technology application suitable for China's leisure agriculture park.

\section{Planning Area Overview and Application Framework}

\subsection{Planning Area}

Covering an area of about 5.05 hectares, the leisure agriculture park is located in Qinyang City, Henan Province. The base has proper climate, fertile soil and good water source, which is extremely favorable to the agricultural production. The transportation is quite convenient around the park, which provides a good basis for the development of leisure tourism. According to market analysis and cost-benefit analysis, this park aims at producing green products and providing leisure and recreation. It integrates smart technology into the park's production management, logistics and sales, which promotes the sustainable development of the park through the improvement of efficiency and inputoutput ratio. Figure 1 shows the function division of the park.

\subsection{Application Framework of Smart Technology}

The application of smart technology centers on integration platform, including smart

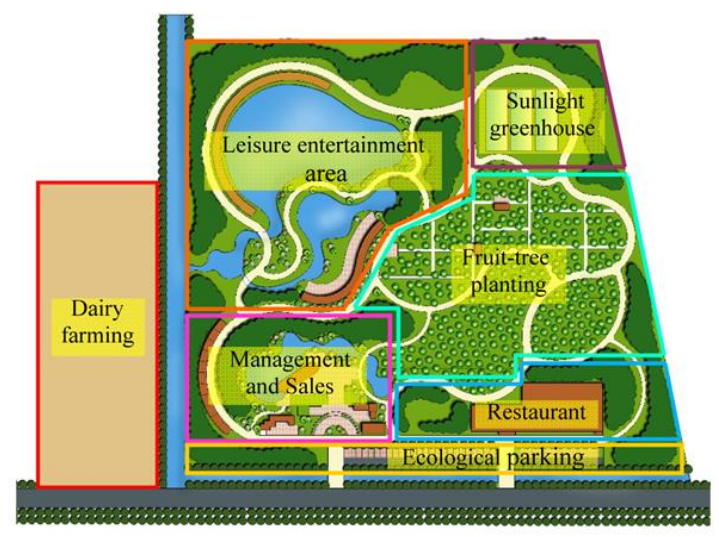

Figure 1. Function Division of the Park

cultivation, smart planting, smart sunlight greenhouse, virtual park, visualization, smart logistics and smart sale module, and forms a hierarchical structure consisting of perception layer, network layer, application layer, platform layer and service layer. When realizing smart technology application to the planning, we should combine the characteristics of functional areas with the characteristics of spatial layout. The same module can be distributed in different functional areas, and different modules can be applied to the same functional areas, providing smart service for the park through the efficient network system (Figure 2). 


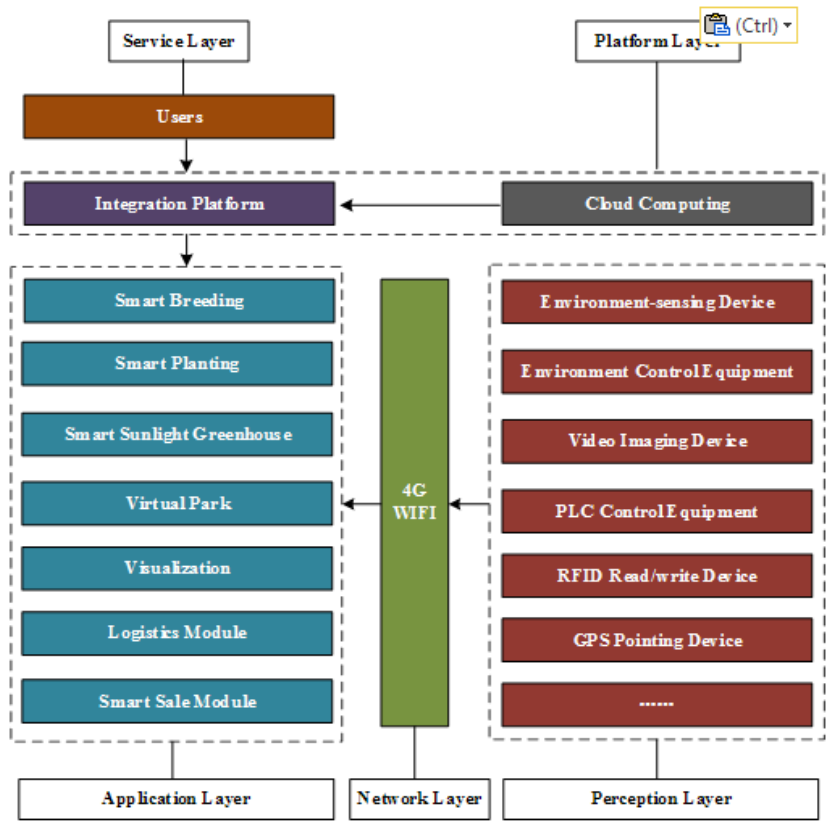

Figure 2. Application Framework of Smart Technology

\section{Technology Application of Smart Module}

The organizational structure of the smart module and the rationality of technique matching will influence the overall efficiency of the system. The internal functional organization of the module should be reasonable and perfect and meet operational requirements. Different modules should be able to realize coordination and conformity to facilitate the sharing of resources and data transmission (Figure 3).

\subsection{Smart Breeding}

According to market demands, the park has a plan for a standardized farm for milk cows, providing milk source of high quality to community residents and enterprises. The farm applies RFID technology to implement strict tracking and management over milk cows. The electronic identification devices installed inside the cows' collars can store a lot of information including the cow's family history, place of origin, per unit yield, amount of milk, age, time of milking and physical status, and it can be continuously enriched and improved during the processes of cow raising, transporting, and milking. Meanwhile, those information will be integrated in detail into the "Traceable Information System for Quality Safety of Dairy Products" to facilitate the query of the general public. Smart breeding can ensure the health of dairy cows and provide quality products at the same time, thus meeting consumers' requirement for food security and quality.

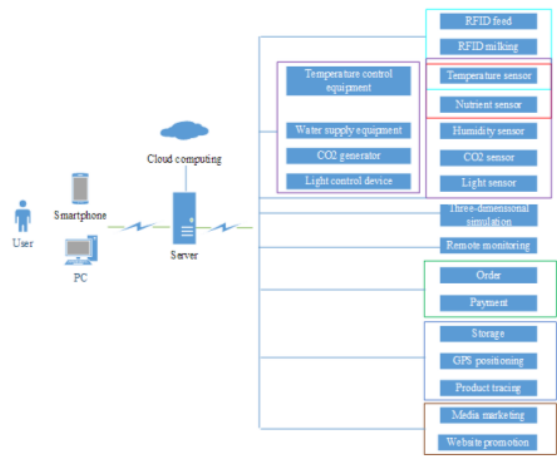

Figure 3. Technology Application of Smart Module 


\subsection{Smart Planting}

The main service objects of smart planting are fruit trees and vegetables growing in the open. Outdoor planting has high demands on water and nutrient of soil environment, especially on water. Smart irrigation can keep accurate control of the supply of moisture. Its basic principle is: the humidity signal collected by the humidity sensor, after conversion, will enter programmable controller, and when irrigation is required, the opening and closing of water pump and electromagnetic valve can be controlled by the control signal. As for soil nutrient, the information will be collected by the nutrient sensor and after that the generated graphs will be provided to management personnel for reference.

\subsection{Smart Sunlight Greenhouse}

A cost-effective smart sunlight greenhouse is planned in the park. Inside the greenhouse, temperature, humidity, the concentration of carbon dioxide, illumination and other indicators can be detected by sensors, and after the information is passed to the processing center, according to set values, the control software issues instructions to actuators such as automatic control pump, heater, generating equipment of carbon dioxide, and lighting control device to realize automatic control of production environment.

\subsection{Virtual Park}

A website of the park is planned, to establish a virtual agriculture park area with threedimensional roaming function, offering the public with navigation and real-time information query service. The landscapes, scenic spots, leisure and parking facilities of the park can be queried at any time so that tourists can choose according to their current situation. Meanwhile, tourists can upload real-time landscapes of the park and other information to the three-dimensional platform to realize interactions.

\subsection{Visualization}

Remote visualization refers to the service provided by video monitoring for production and management. Camera devices are equipped in the park, especially on the farm, and in the sunlight greenhouse, field planting area, eco-canteen etc., which could realize remote visualization of the growing environment of animals and plants and make it more convenient for the managers to supervise and experts to diagnose.

\subsection{Logistics Module}

Agricultural products are required to be non-pollution and non-deterioration in the logistics process, which is different from industrial products. In addition, since the price of agricultural products is relatively low, the logistics should operate at a low cost. The aim of smart logistics is to achieve the whole-process supervision "from seed to table", to guarantee the quality of products by reducing the chance of products being polluted. In the park, pesticides, hormones and fertilizers are strictly prohibited during planting and breeding process in order to ensure products can meet the quality standard. In addition, in order to provide good quality products for consumers, it also needs to strengthen the monitoring in the process of production and transportation. This park's products are mainly provided to local market, so the planned refrigeration storage and delivery system will deliver the products to consumers in time.

\subsection{Smart Sale Module}

Smart sale is a marketing method that is to achieve marketing target through Internet, computers, communications technology and digital interactive media. This system helps 
the park to exploit the market and attract consumers quickly and efficiently, makes the enterprise march towards the market with a relatively low cost and at a comparatively rapid pace to satisfy the demand of customers. The module is based on the need of customer individuation, and it forms a service system integrating commodity information, bills collection and after-sales service.

\section{Conclusions}

Smart agriculture is the advanced stage of agriculture production. Blending smart technology into leisure agriculture parks, sufficiently using modern information technology achievements, integrating computer and network technology, the technology of the Internet of Things, audio and video technology, 3S technology, wireless communication technology and wisdom and knowledge of experts, are helpful to improve the park's efficiency of production management and economic benefit. The market prospect of using the smart technology in leisure agriculture parks is very broad.

\section{Acknowledgements}

This project is financially supported by the Science and Technology Innovation Fund Project of Young Teachers in Henan Institute of Science and Technology, 2014 (Project title: Research on the Planning and Coordinated Mechanism of Smart Agriculture Science and Technology Demonstration Park) and The Key Scientific Research Project of Universities in Henan Province (Project number is: 15B220001).

\section{References}

[1] L. Hongqing and L. Liming, "Function orientation and evaluation framework for modern suburban agriculture, a case study of Beijing metropolis", Ecology and Environmental Sciences, vol. 19, no. 6, (2010), pp. 1428-1433.

[2] Q. -S.Kong, H. -Y.Li and W. -LShi, "Evaluation of leisure agriculture based on DEA in Hebei Province - the case of Hebei leisure agriculture and rural tourism demonstration sites", Chinese Journal of Eco-Agriculture, vol. 21, no. 4,(2013), pp. 511-518.

[3] Z. Chen, Y.Ju-sheng, M.Jia, L. Qiang andC.g Bin-bin, "Research on developing low-carbon leisure agriculture in Shangha”, ActaAgriculturae Shanghai, vol. 29, no. 5, (2013), pp. 137-141.

[4] S.Paroutis, M. Bennett and L.Heracleous, "A strategic view on smart city technology: The case of IBM Smarter Cities during a recession", Technological Forecasting and Social Change, vol. 89,(2014), pp. 262-272.

[5] R. Morimoto, "A socio-economic analysis of Smart Infrastructure sensor technology", Transportation Research Part C, Emerging Technologies, vol. 31, (2013), pp. 18-29.

[6] J. A. Delgado, K. Kowalski and C.Tebbe, "The first Nitrogen Index app for mobile devices, Using portable technology for smart agricultural management", Computers and Electronics in Agriculture, vol. 91, (2013), pp. 121-123. 


\section{Authors}

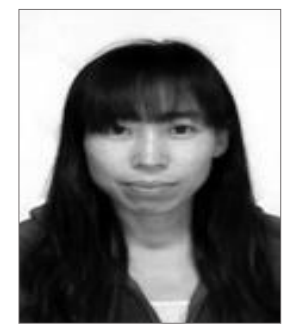

LifangQiao, female, She received a Master degree from Central South University of Forestry and Technology, Changsha, China, in 2004, now she is an associate professor in the School of Horticulture and Landscape Architecture of Henan Institute of Science and Technology, Xinxiang, China. Her current research interests include the landscape evaluation and the application of mathematical models in landscape optimization. E-mail: qiaolifang2002@163.com.

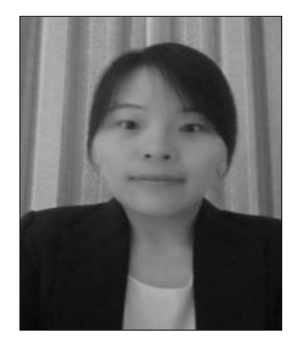

Lili Song, female, she received a Master degree from China Agriculture University, Beijing, China, in 2006. Now she is a lecture in the School of Horticulture and Landscape Architecture of Henan Institute of Science and Technology, Xinxiang, China. Her current research interests include the urban planning and urban design.Email: 252736256@qq.com.

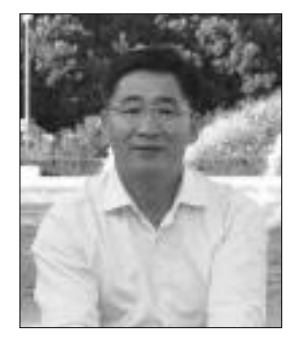

Xinzheng Li, male, professor, School of Horticulture and Landscape Architecture, Henan Institute of Science and Technology, mainly engaged in the research about planning of Agricultural Demonstration Park. E-mail: lixinzheng@ @ist.edu.cn. 